\title{
Extraction and Antioxidant Activity of Soybean Saponins from Low- temperature Soybean Meal by MTEH
}

\author{
Liu Zhong-Hua ${ }^{*}$, Ge Hong-Lian, Luo Rui-Ling and Zhao Jin-Hui \\ College of Life Science and Agronomy, Zhoukou Normal University, Zhoukou, Henan, 466000, China
}

\begin{abstract}
The research aimed at developing an optimal procedure for the extraction of soybean saponins from lowtemperature soybean meal with microwave treatment combined with enzymatic hydrolysis (MTEH), and studied the antioxidant activity of soybean saponins. The result shows that the optimal parameters of microwave treatment, determined with the orthogonal array design method, were the medium fire of microwave power, 1.5 min of microwave time, $80 \%$ of ethanol, and 1:25 ratio of material to water, moreover, the optimal conditions of enzymatic hydrolysis, determined with the response surface experiments, were 50 minutes of hydrolysis time, $51^{\circ} \mathrm{C}$ of hydrolysis temperature and $1.5 \%$ dosage of cellulase, with which the optimal extraction ratio of the soybean saponins reached $0.916 \%$. The saponins extracted from soybean meal exhibited antioxidant activity and the effect of scavenging superoxide anion radicals (SAR) and hydrogen peroxide $\left(\mathrm{H}_{2} \mathrm{O}_{2}\right)$.
\end{abstract}

Keywords: Soybean saponina, microwave, enzymatic hydrolysis, antioxidant activity.

\section{INTRODUCTION}

Recently, physiologically active substances from soybean, such as soybean saponins, and soybean isoflavone, have become a hot topic in the researches based on industry of health foodstuff. Soybean saponins have various physiological functions, such as anti-lipid oxidation, antifree radical, immune regulation, anticoagulation, antithrombotic, anti-diabetic, antitumor and antivirus $[1,2]$. Low-temperature soybean meal, produced as a by-product in the process of extracting oil from soybean, with low price and large yield in China, contains rich soybean saponins. The research studied the method of extraction of soybean saponins from the raw materials, and soybean meal, to make full use of the potential value of soybean meal.

Currently, the researches mainly focus on the physiological activity of soybean saponins and less focus on the extraction technology to improve the extraction ratio of soybean saponins, which is the key to extract the highpurified products [3]. Microwave extraction, is efficient, highly selective and has no pollution hazards as compared to the traditional solvent extractions. It is one of the new technologies used to extract the biological active substances $[4,5]$. The method of biological enzyme hydrolysis, with strong selectivity and high efficiency, is widely used for extracting effective components from plants [6].

*Address correspondence to this author at the College of Life Science and Agronomy, Zhoukou Normal University, Zhoukou, Henan, 466000, China; Tel: 13839439312; E-mail: 1zh.hzl@163.com
The researches based on the methods of microwave treatment combined with enzymatic hydrolysis to extract the soybean saponins from low-temperature soybean meal are less reported. The research for improving efficiency and making full use of soybean meal, studied the process condition of microwave treatment combined with enzymatic hydrolysis to extract the soybean saponins from lowtemperature soybean meal to provide a more efficient method for extracting soybean saponins and obtain basic data for large-scale industrial production. In addition, the research studied the antioxidant activity of soybean saponins extracted from low-temperature soybean meal to provide scientific basis for its further exploration.

\section{MATERIALS AND METHODS}

\subsection{Materials and Reagents}

Low-temperature Soybean meal was offered by Henan Zhoukou Yihai Grain and Oil Co Ltd; Cellulase enzyme $(20000 \mathrm{U} / \mathrm{g})$. Oleanolic acid of standard substance, ethanol, petroleum ether were analytically pure.

\subsection{Methods}

Pretreatment of raw material. The grinded soybean meal was screened through 80 mesh sieve and treated with solvent of petroleum ether to carry out soxhlet extraction for about $3 \mathrm{~h}$, with the ratio of solid-liquid at the 1:15; the defatted soybean meal was dried for reserve. 
Drawing of standard curve of soybean saponins. With the oleanolic acid used as a standard acid, the standard curve was drawn [7]. The oleanolic acid methanol solution was drawn with the following volume of $0 \mathrm{~mL}, 0.2 \mathrm{~mL}, 0.4 \mathrm{~mL}$, $0.6 \mathrm{~mL}, 0.8 \mathrm{~mL}$, and $1 \mathrm{~mL}$ respectively, poured into different volumetric flasks of $10 \mathrm{~mL}$, and diluted with the $95 \%$ ethanol to $10 \mathrm{~mL}$; the control group had $95 \%$ ethanol. The ODs were measured at a wavelength of $210 \mathrm{~nm}$, and the quality of concentration by absorbance was regressed with the regressed equation: $\mathrm{A}=88.350 \mathrm{C}+0.0611\left(\mathrm{R}^{2}=0.9930\right)$.

Extraction and measurement of soybean saponins. The defatted soybean meal was treated by cellulase, and then saponins in the cellulase-lyzed solution were extracted in the solvent of ethanol with microwave treatment . The extracted solution was diluted to 20 folds with $95 \%$ ethanol for measuring its OD at a wavelength of $210 \mathrm{~nm}$. The content of soybean saponins was calculated with the regressed standard curve.

Calculation of the ratio of soybean saponins. The ratio of soybean saponins $(\%)=$ the content of soybean saponins (g) / sample mass $(\mathrm{g}) \times 100$

Optimization on extraction conditions of soybean saponins. Different microwave treatments, including concentration of ethanol, ratio solid-liquid, microwave power and microwave time, and the parameters of enzymatic hydrolysis, including enzyme usage, enzymolysis time, hydrolysis temperature and $\mathrm{pH}$ value, were studied in singlefactor experiments to investigate their effect on the extraction ratio of soybean saponins. Based on the singlefactor experiments, the orthogonal experiments and response surface experiments were applied to optimize the extraction condition of soybean saponins.

Measurement of antioxidant activity of soy saponins from soybean meal. The scavenging effect of soybean saponins on SARs was detected with the methods of pyrogallol autoxidation [8]. The scavenging effect of soybean saponins on $\mathrm{H}_{2} \mathrm{O}_{2}$ was detected with the method of spectrophotometry [9].

\section{RESULTS AND ANALYSIS}

\subsection{Single-factor Experiments of Microwave Treatment}

Microwave time. Soybean meal treated with cellulase was extracted with $60 \%$ ethanol and the ratio of solidliquid was 1:20, and the solution was treated with microwave at medium fire for $0 \mathrm{~min}, 0.5 \mathrm{~min}, 1.0 \mathrm{~min}, 1.5$ $\mathrm{min}, 2.0 \mathrm{~min}$, and $2.5 \mathrm{~min}$, and the experiment was repeated for three times. The results areshown in Fig. (1).

Fig. (1) shows that the longer the microwave time, the higher the extraction ratio of soybean saponins. The extraction ratio increased to a peak value with the treatment time of $1.0 \mathrm{~min}$, but then decreased with the extension of time. The possible reason for the decrease in ratio might be protein denaturation of the soybean meals caused by increased microwave time, which blocked the infiltration and diffusion of soybean saponins. Therefore, the optimal time of microwave treatment was $1.0 \mathrm{~min}$ for extracting soybean saponins among the experiments.

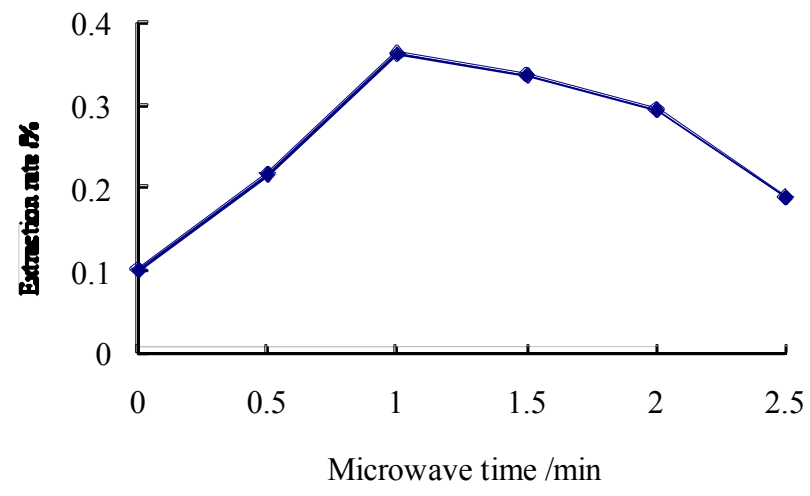

Fig. (1). Effect of different microwave time on the extraction rate of soybean saponina.

Ratio of solid-liquid. Soybean meal treated with cellulase was extracted with $60 \%$ ethanol and the ratio of solid-liquid was 1:10, 1:15, 1:20, 1:25, and 1:30, respectively, and the solution was treated with microwave at medium fire for $1.0 \mathrm{~min}$. The experiment was repeated for three times. The result is shown in Fig. (2).

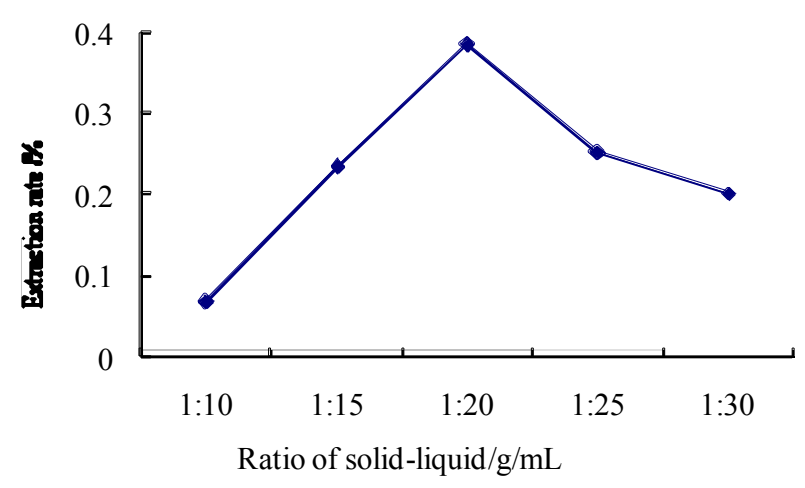

Fig. (2). Effect of different ratio of solid-liquid on the extraction rate of soybean saponina.

Fig. (2) shows that the bigger the ratio of solid-liquid, the higher the extraction ratio of soybean saponins. The extraction ratio increased to a peak value at 1:20, but then decreased with the increase in the ratio of solid-liquid. Thus, the optimal ratio of solid-liquid was 1:20 for extracting soybean saponins among the experiments.

Concentration of ethanol. Soybean meal treated with cellulase was extracted with $50 \%, 60 \%, 70 \%, 80 \%, 90 \%$, and $100 \%$ ethanol and the ratio of solid-liquid was $1: 20$, and the solution was treated with microwave at medium fire for $1.0 \mathrm{~min}$. The experiment was repeated three times. The result is shown at Fig. (3).

Fig. (3) shows that the bigger the concentration of ethanol, the higher the extraction ratio of soybean saponins. The extraction ratio increased to the peak value with the concentration of ethanol at $80 \%$, but decreased with the increase inthe concentration. The possible reason for the decrease in the ratio might be the change in the polarity of extraction solution, which blocked the infiltration and diffusion of soybean saponins, thus, the optimal 
concentration of ethanol was observed to be $80 \%$ for extracting soybean saponins among the experiments.

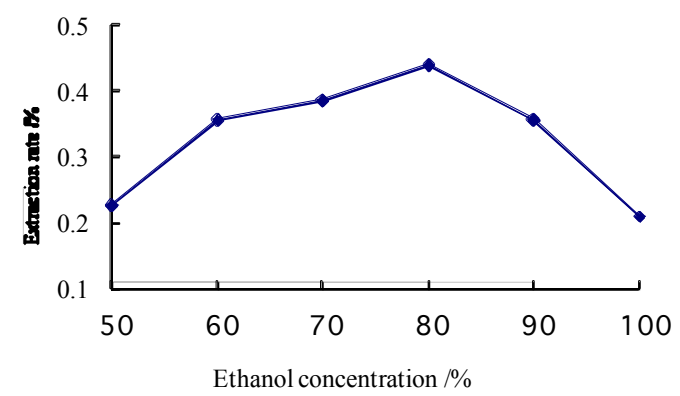

Fig. (3). Effect of different ethanol concentration on the extraction rate of soybean saponins.

Microwave power. Soybean meal treated with cellulase was extracted with $80 \%$ ethanol and the ratio of solid-liquid was 1:20, and the solution treated with microwave treatment at low-power, thawing, medium fire, medium-high fire, high fire for $1.0 \mathrm{~min}$. The experiment was repeated three times. The result isshown in Fig. (4).

Fig. (4) shows that the stronger the microwave power, the higher the extraction ratio of soybean saponins. The extraction ratio increased to a peak value with the medium fire, but decreased with the increase in the microwave power. The possible reason for the decrease in the ratio might be the decomposition of the soybean saponins caused by microwave power. Thus, the optimal microwave power was the medium fire for extracting soybean saponins among the experiments.

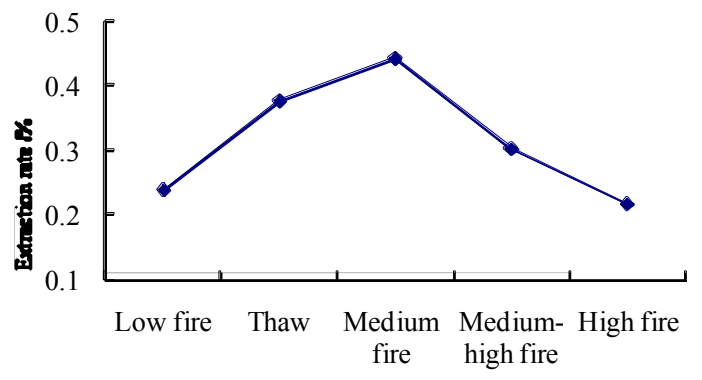

Microwave power

Fig. (4). Effect of different microwave power on the extraction rate of soybean saponins.

\subsection{Orthogonal Experiment of Microwave Conditions}

Based on experimental results of the single-factor microwave treatment, the experiment of $\mathrm{L}_{9}\left(3^{4}\right)$ orthogonal (Table 1) was conducted to optimize the parameters in microwave treatment. The results of orthogonal experiment are shown in Table 2.

Table 2 shows that the factors influencing the extraction ratio of soybean saponins from soybean meal were; microwave time (C), microwave power (B), ethanol concentration (A), ratio of solid-liquid (D) in the order from the strongest to the weakest; the optimal combination of treatment for extraction was $\mathrm{A}_{2} \mathrm{~B}_{2} \mathrm{C}_{3} \mathrm{D}_{3}$ : ethanol $80 \%$, microwave power at medium fire, microwave treatment time of $1.5 \mathrm{~min}$, and $1: 25 \mathrm{~g} / \mathrm{mL}$ ratio of solid-liquid.

\subsection{Single Factor Experiment of Enzymolysis Condition}

Enzyme dosage. With the cellulase enzymolysis buffer of $\mathrm{pH} 6.0$ and the enzymolysis temperature at $45^{\circ} \mathrm{C}$, the solution was extracted with $0 \%, 0.5 \%, 1.0 \%, 1.5 \%, 2.5 \%$, and $3.0 \%$ of cellulase enzymolysis dosage for $30 \mathrm{~min}$, respectively, and subsequently treated with the above mentioned optimal condition for microwave treatment.

With an increasein the enzyme dosage, the extraction ratio of soybean saponins also increased gradually (Fig. 5). At $1.5 \%$ of the enzyme dosage, the extraction ratio reached the maximum, but gradually decreased with the continued increase in the enzyme dosage. This suggested that the optimal enzymolysis dosage was $1.5 \%$ for the extraction of soybean saponins among the experiments.

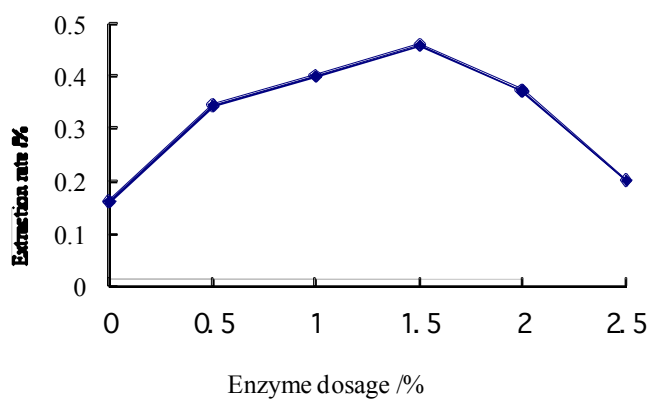

Fig. (5). Effect of different enzyme dosage on the extraction rate of soybean saponins.

PH value.With cellulase dosage of $1.5 \%$, extraction solution was treated with the cellulase enzymolysis buffer liquid of $\mathrm{pH} 2.0,3.0,4.0,5.0,6.0$, and 7.0, respectively, and was hydrolysed for $30 \mathrm{~min}$ at $45^{\circ} \mathrm{C}$ to extract the saponins with the above mentioned optimal condition for microwave treatment. The experiment was repeated three times and the results are shown in Fig. (6).

Fig. (6) shows that at $\mathrm{pH} 4.0$ of the cellulase enzymolysis buffer liquid, the extraction ratio of soybean saponins reached the peak, and at other $\mathrm{pH}$ values, the extraction ratios were lower. The most suitable $\mathrm{pH}$ of cellulase enzymolysis buffer for extracting soybean saponins was 4.0. Thus, the most optimal $\mathrm{pH}$ value was 4.0 and dosage of the enzymatic hydrolysis was $1.5 \%$ for extracting soybean saponins among the experiments.

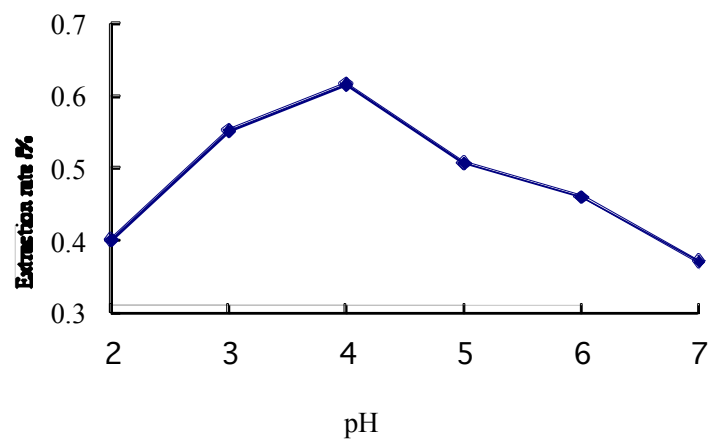

Fig. (6). Effects of different ph on the extraction rate of soybean saponins. 
Table 1. Factor and levels in orthogonal array design.

\begin{tabular}{|c|c|c|c|c|}
\hline \multirow[b]{2}{*}{ Levels } & \multicolumn{4}{|c|}{ Factors } \\
\hline & $\begin{array}{c}\text { A } \\
\text { Ethanol Concentration/\% }\end{array}$ & $\begin{array}{c}\text { B } \\
\text { Microwave Power }\end{array}$ & $\begin{array}{c}\text { C } \\
\text { Microwave Time/min }\end{array}$ & $\begin{array}{c}\text { D } \\
\text { Ratio of Solid-Liquid } /(\mathrm{g} / \mathrm{mL})\end{array}$ \\
\hline 1 & 70 & thaw & 0.5 & $1: 15$ \\
\hline 2 & 80 & medium fire & 1.0 & $1: 20$ \\
\hline 3 & 90 & medium-high fire & 1.5 & $1: 25$ \\
\hline
\end{tabular}

Table 2. The results of orthogonal experiment.

\begin{tabular}{|c|c|c|c|c|c|}
\hline \multirow{2}{*}{$\begin{array}{l}\text { Experiment } \\
\text { Number }\end{array}$} & \multicolumn{4}{|c|}{ Factor } & \multirow{2}{*}{$\begin{array}{c}\text { Soybean Saponins } \\
\text { Extraction/ (\%) }\end{array}$} \\
\hline & A & B & C & D & \\
\hline 1 & 1 & 1 & 1 & 1 & 0.435 \\
\hline 2 & 1 & 2 & 2 & 2 & 0.317 \\
\hline 3 & 1 & 3 & 3 & 3 & 0.551 \\
\hline 4 & 2 & 1 & 2 & 3 & 0.353 \\
\hline 5 & 2 & 2 & 3 & 1 & 0.765 \\
\hline 6 & 2 & 3 & 1 & 2 & 0.482 \\
\hline 7 & 3 & 1 & 3 & 2 & 0.517 \\
\hline 8 & 3 & 2 & 1 & 3 & 0.611 \\
\hline 9 & 3 & 3 & 2 & 1 & 0.298 \\
\hline $\mathrm{R}$ & 0.099 & 0.129 & 0.288 & 0.066 & \\
\hline
\end{tabular}

Cellulase hydrolysis temperature. With the cellulase enzymolysis buffer liquid at $\mathrm{pH} 4.0$ and $1.5 \%$ of enzyme dosage, the solution of enzymatic hydrolysis was treated at different temperatures $40^{\circ} \mathrm{C}, 45^{\circ} \mathrm{C}, 50^{\circ} \mathrm{C}, 55^{\circ} \mathrm{C}$, and $60^{\circ} \mathrm{C}$ for $30 \mathrm{~min}$ to extract the saponins, respectively, with the above mentioned optimal condition for microwave treatment. The experiment was repeated three times and the results are shown in Fig. (7).

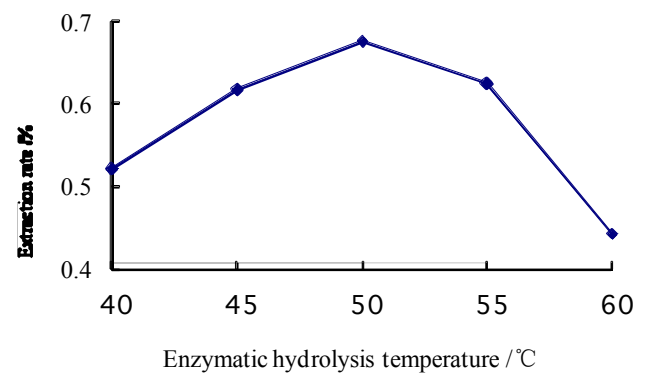

Fig. (7). Effects of different enzymatic hydrolysis temperature on the extraction rate of soybean saponins.
Fig. (7) shows that with the rise in the temperature of enzymatic hydrolysis, the extraction ratio of soybean saponins increased gradually. At $50^{\circ} \mathrm{C}$ of the enzymatic hydrolysis temperature, the extraction ratio reached the maximum, but gradually decreased with the continued rise in the temperature of enzymatic hydrolysis. The possible reason for the decrease in the extraction ratio might be the inhibition or deactivation of the cellulase activity, which was the result of the high temperature. Thus, the optimal enzymatic hydrolysis temperature was $50^{\circ} \mathrm{C}$ for extracting soybean saponins among the experiments.

Enzymatic hydrolysis time. With the cellulase hydrolysis buffer liquid at $\mathrm{pH} 4.0$ and the dosage of cellulase at $1.5 \%$, the extraction solution was hydrolysed for $20 \mathrm{~min}$, $30 \mathrm{~min}, 40 \mathrm{~min}, 50 \mathrm{~min}$, and $60 \mathrm{~min}$ at $50^{\circ} \mathrm{C}$ to extract the saponins with the above mentioned optimal condition for microwave treatment, respectively. The experiment was repeated three times and the results are shown in Fig. (8). 


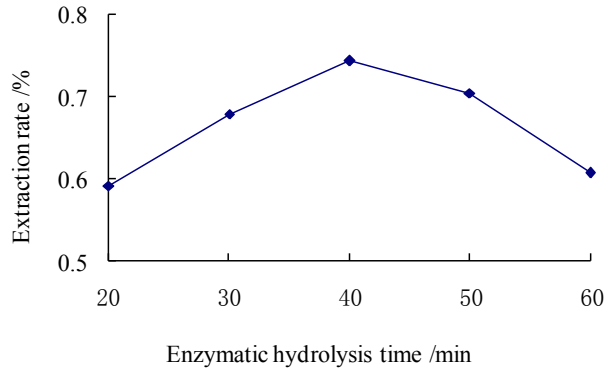

Fig. (8). Effect of different enzymatic hydrolysis time on the txtraction rate of soybean saponins.

Fig. (8) shows that with increased enzymolysis time, the extraction ratio of soybean saponins also increased. At 40 min of the hydrolysis time, the extraction ratio reached the maximum, but decreased with the hydrolysis time over 40 minutes. Therefore, the most suitable hydrolysis time was 40 minutes for the extraction of soybean saponins among the experiments.

\subsection{The Response Surface Experiments of Enzymatic Hydrolysis Conditions}

Based on the principle of Box-Benhnken central composite design, and with the most suitable condition of microwave treatment for extraction and the results of singlefactor enzymatic hydrolysis experiments, the enzymatic hydrolysis condition of soybean saponins was optimized with the method of response surface (RSM) and the factor level of RSM isshown in Table 3. The experimental results of RSM areshown in Table $\mathbf{4}$ and Table $\mathbf{5}$.

Based on the test data represented in Table 4, the effect of cellulase dosage, and the temperature and time of enzyme

Table 3. Factor and levels in Box-Behnken central composite design.

\begin{tabular}{|c|c|c|c|}
\hline \multirow{2}{*}{ Levels } & \multicolumn{2}{|c|}{ Factors } \\
\cline { 2 - 4 } & E & B & C \\
& Enzyme Dosage/\% & Enzymatic Hydrolysis Temperature $/{ }^{\circ} \mathbf{C}$ & 30 \\
\hline \hline 1 & 1.0 & 45 & 40 \\
\hline 2 & 1.5 & 50 & 50 \\
\hline 3 & 2.0 & 55 & 50 \\
\hline
\end{tabular}

Table 4. Results of Box-Behnken central composite design.

\begin{tabular}{|c|c|c|c|c|}
\hline $\begin{array}{l}\text { Experiment } \\
\text { Number }\end{array}$ & $\begin{array}{c}\text { A } \\
\text { Enzyme Dosage/\% }\end{array}$ & $\begin{array}{c}\text { B } \\
\text { Enzymatic Hydrolysis } \\
\text { Temperature } /{ }^{\circ} \mathrm{C}\end{array}$ & $\begin{array}{c}\text { C } \\
\text { Enzymatic Hydrolysis } \\
\text { time/min }\end{array}$ & $\begin{array}{c}\text { Soybean Saponins } \\
\text { Extraction/ (\%) }\end{array}$ \\
\hline 1 & 1.0 & 50 & 50 & 0.861 \\
\hline 2 & 2.0 & 50 & 50 & 0.896 \\
\hline 3 & 1.5 & 50 & 40 & 0.890 \\
\hline 4 & 1.0 & 45 & 40 & 0.573 \\
\hline 5 & 1.5 & 50 & 40 & 0.887 \\
\hline 6 & 1.5 & 45 & 50 & 0.695 \\
\hline 7 & 2.0 & 45 & 40 & 0.660 \\
\hline 8 & 1.5 & 50 & 40 & 0.874 \\
\hline 9 & 1.5 & 55 & 30 & 0.729 \\
\hline 10 & 1.5 & 50 & 40 & 0.879 \\
\hline 11 & 2.0 & 50 & 30 & 0.882 \\
\hline 12 & 1.0 & 55 & 40 & 0.722 \\
\hline 13 & 1.0 & 50 & 30 & 0.717 \\
\hline 14 & 2.0 & 55 & 40 & 0.731 \\
\hline 15 & 1.5 & 55 & 50 & 0.769 \\
\hline 16 & 1.5 & 50 & 40 & 0.882 \\
\hline 17 & 1.5 & 45 & 30 & 0.737 \\
\hline
\end{tabular}


Table 5. ANOVA for the regression response surfuce model.

\begin{tabular}{|c|c|c|c|c|c|c|}
\hline Source & DF & Sum of Squares & Mean Square & F value & Prob $>$ F & \\
\hline Mode 1 & 9 & 0.15 & 0.017 & 15.52 & 0.0008 & $* *$ \\
\hline B & 1 & 0.01 & 0.01 & 9.32 & 0.0185 & $*$ \\
\hline $\mathrm{A}^{2}$ & 1 & 0.011 & 0.011 & 10.46 & 0.0144 & $*$ \\
\hline $\mathrm{B}^{2}$ & 1 & 0.11 & 0.11 & 96.68 & $<0.0001$ & $* *$ \\
\hline $\mathrm{C}^{2}$ & 1 & 0.000326 & 0.000326 & 0.3 & 0.6025 & \\
\hline $\mathrm{AB}$ & 1 & 0.00152 & 0.00152 & 1.39 & 0.2774 & \\
\hline Residual & 7 & 0.00768 & 0.0011 & & & \\
\hline Lack of fit & 3 & 0.00752 & 0.00251 & 2.17 & 0.058 & \\
\hline Pure error & 4 & 0.000161 & 0.0000403 & & & \\
\hline Cor total & 16 & 2.16 & & & & \\
\hline
\end{tabular}

hydrolysis during on the extraction of soybean saponins wereanalyzed with the software of Design Expert to do multiple regressions, and the acquired ternary quadratic response surface regression equation was:

$$
\begin{aligned}
& \mathrm{Y}=-16.01810+1.35040 \mathrm{~A}+0.63725 \mathrm{~B}-0.015840 \mathrm{C}- \\
& 0.20880 \mathrm{~A}^{2}-0.006348 \mathrm{~B}^{2}+0.000088 \mathrm{C}^{2}-0.0078 \mathrm{AB}- \\
& 0.0065 \mathrm{AC}+0.00041 \mathrm{BC}\left(\mathrm{R}^{2}=0.9523\right)
\end{aligned}
$$

Table 5 shows that the regression model was very significant $(\mathrm{P}<0.01)$. In terms of $\mathrm{R} 2=0.9523$, the linear relationship between the dependent variable and the examined variable was significant. The model adjusted coefficient $\mathrm{R}^{2} \mathrm{Adj}$ was 0.9109 , indicating that the model could explain $91.09 \%$ variation of the response values with a higher fitting degree. The results of variance analysis show that the one degree of enzyme of dosage (A), and the temperature of enzyme (B), were significant while the time of enzyme hydrolysis (C) was not significant. Moreover, the quadratic terms $\mathrm{A}^{2}$ and $\mathrm{B}^{2}$ were very significant. The factors influencing the extraction ratio of soybean saponins from soybean meal were $\mathrm{A}, \mathrm{B}$ and $\mathrm{C}$ from being the strongest to the weakest, while $\mathrm{A}$ and $\mathrm{B}$ had a stronger effect on the response values and the relationship of the factors for extraction of soybean saponins with the response value in the experiments not being purely linear while some were nonlinear.

The acquired regression model predicted the conditions for enzyme extraction to obtain the maximum response values which included, $50 \mathrm{~min}$ of enzymolysis time, enzymolysis temperature at $50.88{ }^{\circ} \mathrm{C}$ and $1.50 \%$ dosage of cellulase. With these conditions, the extraction ratio of soybean saponins reached $0.916 \%$. Based on the actual operating conditions, the most suitable condition for extracting soybean saponins was $50 \mathrm{~min}$ of enzymatic hydrolysis time, $51^{\circ} \mathrm{C}$ of enzymolysis temperature and $1.5 \%$ dosage of cellulase enzyme.

To test the reliability of the response surface method, three parallel experiments were implemented under the most suitable extraction conditions. The average extraction ratio of saponins for the three parallel experiments was $0.905 \%$ which was slightly different from the theoretical predicted value, indicating that the response surface method could be applied to optimize condition forenzymatic hydrolysis.

\subsection{Antioxidant Activity of Saponins Extracted from Soybean Meal}

Scavenging effect of saponins extracted from soybean meal on SARs. Fig. (9) shows that more radicals were scavenged with increased extracted solution of soy saponins, indicating that the scavenging effect of the extracted solution of soy saponins on SARs was significantly associated with the content of soy saponins. It was concluded that the extracted soy saponins from soybean meal had the ability to scavenge SARs, suggesting that the scavenging activity of the extracted solution on SARs might be related to the extracted soy saponins.

Scavenging effect of saponins from soybean meal to $\mathrm{H}_{2} \mathrm{O}_{2}$. Hydroxyl free radicals produced by the oxidation of $\mathrm{H}_{2} \mathrm{O}_{2}$ through metal ions attack the DNA in cells, cause the tissue injury, and accelerate the process of lipid oxidation reaction. Thus, the strong antioxidant ability of saponins could be proved by the scavenging effect on $\mathrm{H}_{2} \mathrm{O}_{2}$. 


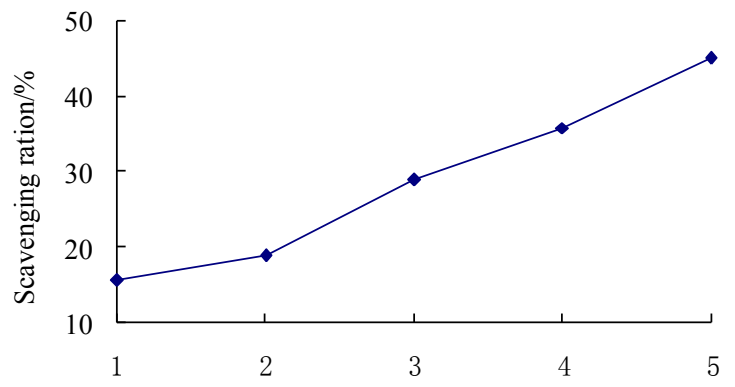

The concentration of saponins/(ug/mL)

Fig. (9). Scavenging effect of saponins from soybean meal on SARs.

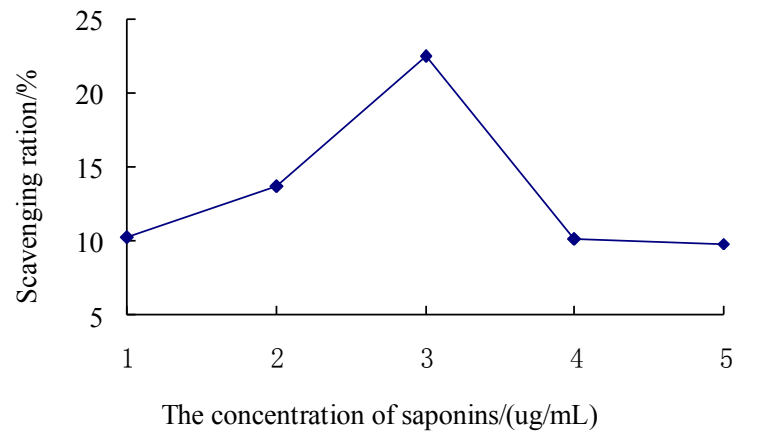

Fig. (10). Scavenging effect of saponins from soybean meal on $\mathrm{H}_{2} \mathrm{O}_{2}$.

Fig. (10) shows that more radicals were scavenged with increase in the concentration of soy saponins. It could be concluded that the extracted soy saponins from soybean meal had the ability to scavenge $\mathrm{H}_{2} \mathrm{O}_{2}$. The highest scavenging ratio of the extracted solution on $\mathrm{H}_{2} \mathrm{O}_{2}$ was $22.5 \%$ with the concentration of soy saponins at $3.0 \mathrm{ug} / \mathrm{mL}$, and the scavenging ratio of $\mathrm{H}_{2} \mathrm{O}_{2}$ decreased with the increase in soy saponins concentration, and the reason for the decrease inscavenging ratio with more soybean saponins remained unclear and needs to be studied further.

\section{CONCLUSION}

This research studied the extraction and antioxidant activity of soy saponins from low-temperature soybean meal by MTEH. The most suitable process condition to extract the saponins with MTEH was $80 \%$ ethanol, medium fire of microwave, $1.5 \mathrm{~min}$ of microwave time, $1: 25 \mathrm{~g} / \mathrm{mL}$ of the ratio material to liquid, $50 \mathrm{~min}$ of cellulase hydrolysis time, $51{ }^{\circ} \mathrm{C}$ of hydrolysis temperature, and $1.5 \%$ of cellulase dosage. Under this condition, the ratio of extraction of soybean saponins reached $0.905 \%$, and the extraction time was markedly shortened, which facilitated their industrial production, while the difference in the function and structure of the extracted soybean saponins from traditional MTEH need to be studied further. It was proved that the extracted solution of soybean saponins had the ability to scavenge SARs and $\mathrm{H}_{2} \mathrm{O}_{2}$, indicating that they had clear antioxidant activity, and that the more radicals were scavenged with the increase in the concentration of the extracted solution of soy saponins, suggesting that its scavenging activity on SARs might be associated with saponins. The more hydrogen peroxide was scavenged with increased concentration of soy saponins, but the ratio of scavenging decreased with increased concentration of the extracted solution of soy saponins, the reason of which needs to be further researched.

\section{CONFLICT OF INTEREST}

The authors confirm that this article content has no conflicts of interest.

\section{ACKNOWLEDGEMENTS}

This work wassupported by the Key Project of Scientific and Technological Research of the Education Department of Henan, China (No. 13A416110).

\section{REFERENCES}

[1] Wang ZY, Ai QJ, Gan JQ, Cheng JW. Research and development of soyasaponins. Cereal Food Indust 1955; 12: 31-34.

[2] Liu SJ, Guan NP, Yan HB. Nutritional and sensory evaluation of soybean meal. Mod J Anim Husbandry Vet Med 2009; 10: 30-32.

[3] Guan WJ, Gu KR. Recent progress of soyasaponin research. Sci Technol Cereals Oils Foods 2007; 15: 42-45.

[4] Upadhyay R, Ramalakshmi K, Rao LJM. Microwave-assisted extraction of chlorogenicacids from green coffee beans. Food Chem 2012; 130: 184-88.

[5] Yang M, Huang FH, Liu CS. Influence of microwave treatment of rapeseed on minor components content and oxidative stability of oil. Food Bioprocses Technol 2013; 6: 3206-16.

[6] Wang JW, Xu YF, Zhou JQ, Chen JL. Advances in enzymeassisted extraction of Chinese traditional medicinal herbs." Chin J Bioprocess Eng 2008; 6: 6-11.

[7] Teng YP, Zhang YM. Determination of soybean saponins by the method of spectrophotometry. Chin J Food Hygiene 2000; 12: 1013.

[8] Zhang LX, Zhao LJ. Study on antioxidant activity of Flammulina velutipes polysaccharide. Southwest China J Agri Sci 2014; 27: 240-3.

[9] Wang HB. The study of antioxidant activity of soyasaponin and isoflavone. Food Res Dev 2008; 29: 9-12.

$\begin{array}{lll}\text { Received: August 27, } 2014 & \text { Revised: November 21, } 2014 & \text { Accepted: December 19, 2014 }\end{array}$

(C) Zhong-hua et al.; Licensee Bentham Open.

This is an open access article licensed under the terms of the Creative Commons Attribution Non-Commercial License (http://creativecommons.org/licenses/ by-nc/4.0/) which permits unrestricted, non-commercial use, distribution and reproduction in any medium, provided the work is properly cited. 